\title{
Subglacial clast/bed contact forces
}

\author{
John BYERS, Denis COHEN, Neal R. IVERSON \\ Department of Geological and Atmospheric Sciences, lowa State University, Ames, IA, USA \\ E-mail: dcohen@iastate.edu
}

\begin{abstract}
A laboratory device was built to measure the forces that ice exerts on a $0.05 \mathrm{~m}$ diameter rigid plastic sphere in two different configurations: in contact with a flat bed or isolated from the bed. Measurements indicated that bed-normal contact forces were 1.8 times larger than drag forces due to creeping flow past a slippery sphere isolated from the bed. Measurements of forces as a function of the bed-normal ice velocity, estimations of the ice viscosity parameter and observations of markers in the ice indicate ice is Newtonian with a viscosity of $\sim 1.3 \times 10^{11} \mathrm{~Pa}$. Newtonian behavior is expected due to small and transient stresses. A model of regelation indicates that it had a negligible $(<5 \%)$ influence on forces. Water pressure in the cavity beneath the sphere in contact with the bed had a likewise negligible influence on contact forces. When no cavity is present, drag forces can be correctly estimated using Stokes's law (Newtonian viscosity) for a slippery sphere. The same law with a bed-enhancement factor of 1.8 is appropriate for estimating bed-normal contact forces. These results reinforce previous laboratory measurements and theories but provide no support for explanations of high debris/bed friction or rates of abrasion that depend on high contact forces.
\end{abstract}

\section{INTRODUCTION}

Basal ice of temperate glaciers contains rock debris in contact with the bed. Entrained by ice and pressed on the bed by bed-normal ice motion, these debris particles exert normal forces and proportional shear forces on the bed, controlling rates of glacial erosion and sliding. Rates of bedrock abrasion and clast comminution are directly related to the magnitude of bed-normal contact forces (Boulton, 1974; Hallet, 1979, 1981; Shoemaker, 1988; Iverson, 1990; Hindmarsh, 1996; Lee and Rutter, 2004). Resultant clast/bed friction increases the resistance to sliding (Reynaud, 1973; Morland, 1976; Hallet, 1981; Schweizer and Iken, 1992; Cohen and others, 2005; Emerson and Rempel, 2007), thereby reducing sliding speed and total ice flux. Effects of ice drag on clasts are not restricted to glaciers on hard beds. Lodgement of clasts in ice on a soft bed will depend on the downward drag that ice exerts on clasts. If the drag is sufficient, clasts will be pushed into the yielding soft bed and lodge there.

Contact forces have been assessed differently in two theories of glacial abrasion (Boulton, 1974; Hallet, 1979). In both theories, debris in contact with the bed is assumed to be sufficiently sparse that particles are isolated. Boulton (1974) suggested that contact forces are controlled by the effective pressure on the bed: the pressure exerted by ice on particles minus the water pressure at the bed surface. The contact force, $F_{\mathrm{C}}$, between a particle and the bed consistent with his formulation can be expressed as $F_{\mathrm{c}}=A p_{\mathrm{e}}$, where $p_{\mathrm{e}}$ is the effective pressure and $A$ is the area over which water pressure acts (Fig. 1a). This area can be expressed as a function of the portion of the particle immersed in water, whether due to a water-filled cavity underneath the particle or to a thin water layer that separates ice at the melting temperature from the bed. In either case $A=\pi\left(2 t R-t^{2}\right)$, where $t$ is the thickness of water in contact with the particle and $R$ is the radius of the particle (Fig. 1a). Even for high effective pressures ( $\sim 1000 \mathrm{kPa})$ and a thick water layer $(1 \mathrm{~mm})$, the contact force between a particle $0.05 \mathrm{~m}$ in radius and the bed does not exceed $300 \mathrm{~N}$.
Hallet (1979) proposed that the contact force depends on the bed-normal drag force on particles due to ice flow toward the bed resulting from local basal melting and/or longitudinal extension of ice (Fig. 1b). He implicitly assumed that $A p_{\mathrm{e}}=0$. Neglecting regelation, the contact force, $F_{\mathrm{C}}$, is equal to the viscous drag, $F_{\mathrm{d}}$, on a sphere isolated from the bed multiplied by a bed-influence factor, $\phi$, which encapsulates effects of the bed on the ice-flow field near the particle and the bed (Hallet, 1981), i.e.

$$
F_{\mathrm{C}}=\phi F_{\mathrm{d}}
$$

Treating ice as a power-law viscous fluid with creep exponent $n$, the drag force on a slippery particle (zero shear stress on its surface) is

$$
F_{\mathrm{d}}=\alpha R^{2} \frac{B}{2}\left(\frac{V}{R}\right)^{1 / n},
$$

where $\alpha$ is a constant that depends on $n$ and particle shape, $R$ is the radius of the particle, $B$ is a viscosity parameter and $V$ is the far-field ice velocity. For a sphere, $\alpha=4 \pi$ for $n=1$ and $8.8 \pi$ for $n=3$ (Lliboutry and Ritz, 1978). This equation also recovers the classical solution of Stokes (Stokes's law) for Newtonian $(n=1)$ flow past a no-slip sphere with no cavity formation when $\alpha=6 \pi$ and $B / 2$ is the viscosity. Hallet (1981), using results of Goren (1970) for a Newtonian fluid, estimated that $\phi=2.4$. For a spherical particle $0.05 \mathrm{~m}$ in radius and for a bed-normal velocity of $0.5 \mathrm{~m} \mathrm{a}^{-1}$, calculations using Hallet's (1981) model yield contact forces of the order of $1000 \mathrm{~N}$.

In a laboratory study of glacial abrasion, Iverson (1990) measured the downward drag force on a sphere in contact with a bed and estimated that $\phi \sim 2$, corroborating Hallet's (1981) theory. Iverson (1990), however, acknowledged several uncertainties associated with ice viscosity, basal heat flux and the presence of water pockets beneath the sphere. No experiments were conducted with a sphere isolated from the bed to help assess the value of $\phi$.

In contrast with these estimates, Cohen and others (2005) measured large (up to $500 \mathrm{kPa}$ ) shear stresses between clasts 
a

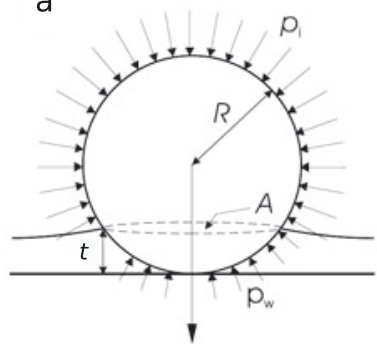

$b$

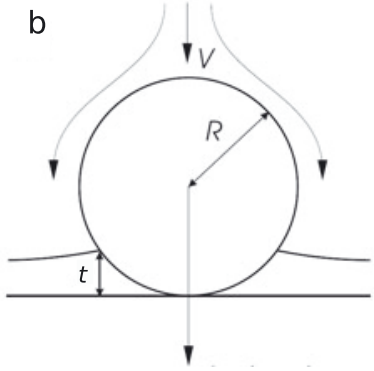

Fig. 1. Conceptual models of clast/bed contact: (a) Boulton (1974) and (b) Hallet (1979). $p_{\mathrm{i}}$ is ice pressure, $p_{\mathrm{w}}$ is water pressure, $R$ is radius of sphere, $A$ is cross-sectional area of sphere at distance $t$ (water film thickness) above the bed and $V$ is downward ice velocity.

and a hard bed at Engabreen, an outlet glacier of the Svartisen ice cap in Norway. They attributed the high shear stress to high bed-normal contact forces. Numerical modeling of ice flow past a sphere in contact with a rigid impermeable bed suggested that $\phi$ could be as high as 100 , but more generally $\sim 10$, for ice with a small creep exponent $(n<2)$ and for small ratios of water film thickness to clast size $(<0.01)$. In another laboratory study of glacial abrasion, Lee and Rutter (2004) also argued that $\phi$ should be $\sim 10$ to reconcile measured rock-on-rock wear rates with abrasion rates inferred from subglacial sediment flux.

Despite their importance, the magnitude of contact forces remains poorly constrained; theories are largely untested and sparse field and laboratory data appear to be contradictory. Herein we discuss measurements of contact forces with a new device constructed to determine the value of the bedenhancement factor, $\phi$. Experiments were designed to also study ice rheology and effects of regelation, water cavities and water pressure on the magnitude of contact forces.

\section{METHODS}

\section{Apparatus}

An apparatus (Fig. 2) was designed to measure drag forces exerted by moving temperate ice on a sphere (representing an idealized particle) both isolated from and resting on the bed (rigid, horizontal surface normal to ice flow). The body of the apparatus is a transparent, acrylic box, herein called the ice chamber, which holds a vertical cylinder of ice $0.305 \mathrm{~m}$ high and $0.200 \mathrm{~m}$ in diameter. The sphere is held stationary as ice moves downward past it due to melting and drainage of meltwater at the bed and due to bed-parallel extension resulting from melting at the walls of the ice chamber. The apparatus resides in a walk-in freezer kept at $2 \pm 1^{\circ} \mathrm{C}$.

A lid made of three circular plates, each $0.20 \mathrm{~m}$ in diameter, is pressed downward onto the top of the ice cylinder by a hydraulic press capable of exerting $1500 \mathrm{kPa}$. This press is built into a sturdy steel loading frame. The lid plates fit snugly into the uppermost $0.079 \mathrm{~m}$ of the ice chamber and are nearly flush with its top when in place initially. Two lid plates made of Delrin ${ }^{\circledR}$ (a strong, lowfriction and low thermal conductivity plastic) sandwich the third plate made of aluminum. Two o-rings surround the uppermost Delrin ${ }^{\circledR}$ plate, sealing against the inner walls of the ice chamber and preventing meltwater produced during experiments from leaking upward out of the ice chamber. The middle aluminum plate contains internal channels through which a temperature-controlled fluid circulates. The low

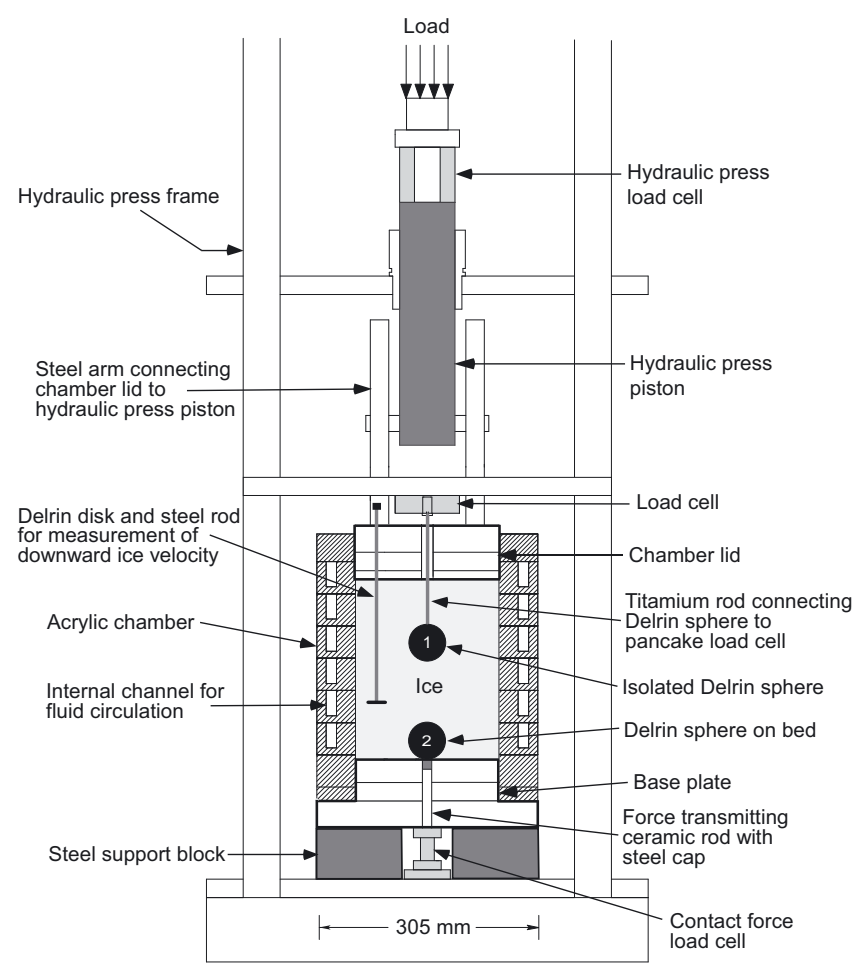

Fig. 2. Apparatus to measure either the drag force past an isolated sphere (sphere labeled 1) or the contact force between sphere and bed (sphere labeled 2). To scale. See text for details.

thermal conductivity of Delrin ${ }^{\circledR}$ insulates ice beneath the lid from the air of the walk-in freezer and helps control the exchange of heat between the ice and the fluid circulating in the aluminum plate.

The bottom of the ice chamber contains a base plate, which fits snugly into the lowermost $0.057 \mathrm{~m}$ of the chamber. The base plate consists of one aluminum plate sandwiched between two Delrin ${ }^{\circledR}$ plates (Figs 2 and 3). Two o-rings surround the upper Delrin ${ }^{\circledR}$ plate, preventing meltwater from leaking downward out of the chamber. Temperature-controlled fluid circulates through a channel in the aluminum plate to control the rate of ice melting at the bed. Three channels in the perimeter of the base plate allow meltwater to drain downward from the bed surface and exit the ice chamber. A fourth, more centrally located port (12 $\mathrm{mm}$ off-center) also drains water from the base plate. The base plate is mounted on steel supports, which hold both the weight of the chamber and load applied by the hydraulic cylinder and also allow for pipes and electrical cables to run beneath the base plate.

Ice temperature is controlled by circulating a fluid in channels that spiral through the walls of the ice chamber (Fig. 2). This fluid enters the walls of the chamber at its base and leaves at its top. Rates of ice melting at the bed are regulated by circulating another fluid through the aluminum plate in the base (Fig. 3). Temperature of the fluids is regulated to a precision of $0.01^{\circ} \mathrm{C}$ outside the freezer by two circulating baths, which also pump the fluid to the apparatus. One bath supplies fluid to the base plate, while the second bath supplies fluid to the ice chamber walls and lid. These separate baths are used to control heat flow independently to the base of the ice cylinder and to its walls and top. In both baths, the fluid is a $4: 1$ mixture of distilled water and glycol. The fluids are transported to and from the apparatus in 
separate plastic tubing systems that run through the freezer wall and are flexible and insulated. By circulating through channels in the ice chamber, chamber lid and base plate, the fluid regulates ice temperature and melt rate more precisely than is possible with the walk-in freezer.

\section{Instrumentation and measurements}

In the isolated-sphere configuration (Fig. 2, sphere labeled 1), drag force on a $50.8 \mathrm{~mm}$ diameter Delrin ${ }^{\circledR}$ sphere, which is held stationary in the center of the ice cylinder, is measured. The sphere is threaded onto the end of a $3.2 \mathrm{~mm}$ diameter titanium rod that extends vertically upward through a small hole in the ice-chamber lid. This rod is attached to a tension/compression load cell (Sensotec, model 41) mounted on a steel frame above the ice chamber. When the cylinder of ice is under a downward stress and at its melting temperature, the ice flows downward as melting occurs at the base and sides of the ice cylinder and water drains from the base of the ice chamber. Ice viscously deforms around the stationary sphere, exerting a drag force that is transmitted through the titanium rod to the load cell. The low thermal conductivity of Delrin ${ }^{\circledR}$ inhibits heat transfer through the ball, which inhibits regelation of ice past the sphere. The lid moves downward with the ice and past the stationary titanium rod. The downward stress applied to the top of the ice cylinder is measured by a three-axis, vibrating-wire load cell (Geokon, model 4900-85-1.375) mounted on the piston of the hydraulic press.

To prevent water from passing between the lid and the titanium rod, a cylindrical plastic plug is epoxied around the rod, and four o-rings surround the plug to seal it against the ice-chamber lid. As the lid moves downward, friction between the lid and plug adds to the total downward force measured by the load cell. Experiments conducted to measure this friction show that it adds $20-25 \mathrm{~N}$ of downward force to the titanium rod. Thus, to obtain the true drag force on the sphere, $22.5 \mathrm{~N}$ are subtracted from all load-cell measurements during isolated-sphere experiments.

In contact-force experiments, the same sphere rests on the top of a $12.7 \mathrm{~mm}$ diameter vertical rod that is flush with the upper surface of the base plate (Fig. 2, sphere labeled 2; Fig. 3). The rod extends downward to a vibrating-wire load cell (Geokon, model 4900X) beneath the apparatus. This rod consists of a $19 \mathrm{~mm}$ long steel cap connected to an underlying $79 \mathrm{~mm}$ long ceramic rod to minimize heat fluxes from below. The sphere is centered on the rod using a $5 \mathrm{~mm}$ diameter hardened-steel pin that extends upward from the steel cap and into a hole at the base of the sphere. This pin fixes the sphere's location over the rod. Two o-rings surround the metal cap and prevent downward drainage of meltwater around the rod. During experiments ice flows downward, exerting a drag on the sphere and pressing it against the rod. The contact force between the sphere and the rod is transmitted through the rod with minimal frictional loss along the o-rings and is recorded by the underlying load cell.

Water pressure in the interfacial film between the ice and base plate is measured with two strain-gauge piezometers (Honeywell, model S) that record fluid pressure in screened ports just below the bed surface (Fig. 3a). One port is near the center of the base plate (14 mm off-center); the second is nearer its perimeter $(60 \mathrm{~mm}$ off-center).

Temperature is measured at multiple locations using miniature, $1.2 \mathrm{~mm}$ diameter, glass-probe thermistors (Yellow
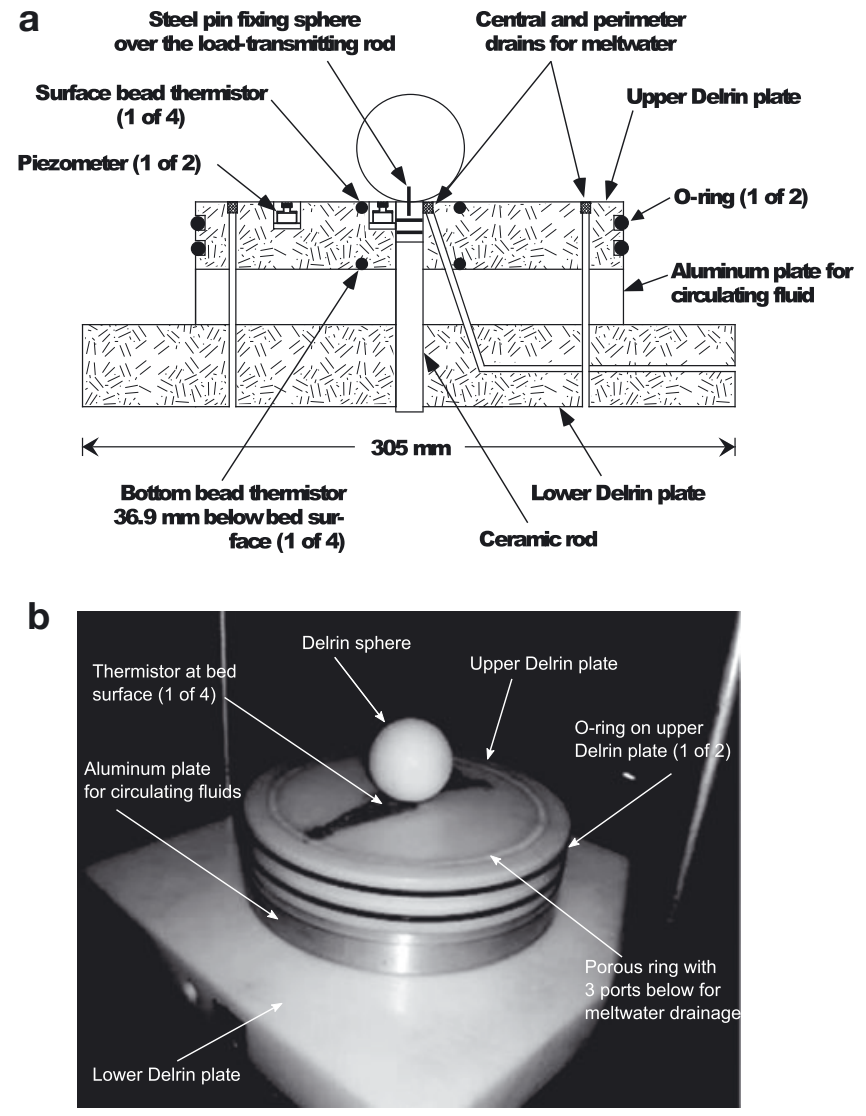

Fig. 3. (a) Cross-sectional drawing of base plate, with major components labeled. To scale. Ports for wires and wiring not shown. (b) Photograph of base plate.

Spring Instrument, model 55034). These thermistors were calibrated to a precision of $5 \mathrm{mK}$ using a mixture of small distilled ice chips and water and a high-precision $(2 \mathrm{mK})$ calibrated thermistor (GEC, model S1TH). Eight thermistors are located in the base plate (Fig. 3): four at the ice/bed interface and four $36.9 \mathrm{~mm}$ beneath the bed surface, to allow computation of heat fluxes and associated basal melt rates. Five thermistors are frozen into the ice cylinder to measure ice temperature. Two additional thermistors are used to measure temperature of the circulating glycol/water mixture immediately before it enters and after it leaves the chamber, to allow computation of the melt rate around the perimeter of the chamber.

The rates of ice melting at the bed, $\dot{m}_{\text {bed, }}$ and around the perimeter of the ice chamber, $\dot{m}_{\text {wall, }}$ are calculated using measured temperature gradients in the bed and chamber walls as follows:

$$
\begin{aligned}
& \dot{m}_{\text {bed }}=\frac{K_{\text {Delrin }}}{\rho L} \frac{\langle T\rangle_{\text {bottom }}-T_{\text {ice }}}{\Delta Z_{\text {Delrin }}}, \\
& \dot{m}_{\text {wall }}=\frac{K_{\text {acryl }}}{\rho L} \frac{\langle T\rangle_{\text {fluid }}-T_{\text {ice }}}{\Delta Z_{\text {acryl }}},
\end{aligned}
$$

where $\rho=917 \mathrm{~kg} \mathrm{~m}^{-3}$ is the density of ice, $L=$ $3.35 \times 10^{5} \mathrm{~J} \mathrm{~kg}^{-1}$ is the latent heat of fusion, $K_{\text {Delrin }}=$ $0.36 \mathrm{~W} \mathrm{~m}^{-1} \mathrm{~K}^{-1}$ and $K_{\text {acryl }}=0.1875 \mathrm{~W} \mathrm{~m}^{-1} \mathrm{~K}^{-1}$ are the thermal conductivities of Delrin ${ }^{\circledR}$ and acrylic, respectively, $T_{\text {ice }}$ is the ice temperature, $\langle T\rangle_{\text {bottom }}$ is the average of thermistor temperatures in the bottom of the upper Delrin ${ }^{\circledR}$ plate of the base (Fig. 3), $\langle T\rangle_{\text {fluid }}$ is the average of the inlet and outlet 
temperatures of the fluid in the ice chamber, $\Delta Z_{\text {Delrin }}=$ $0.0369 \mathrm{~m}$ is the thickness of the Delrin ${ }^{\circledR}$ upper plate (Fig. 3), and $\Delta Z_{\text {acryl }}=0.0262 \mathrm{~m}$ is the thickness of the ice-chamber acrylic wall.

All melting that occurs along the base of the ice cylinder contributes to downward ice movement. Melting along chamber walls removes ice from the perimeter of the cylinder, causing radial extension. This extension induces an additional downward component of ice movement, contributing to the total downward velocity. This downward component of velocity, however, is not uniform and increases upward. The downward ice velocity, $V$, at height $H$ above the bed, obtained from a simple mass balance, is

$$
V(H)=\dot{m}_{\text {bed }}+\frac{2 \dot{m}_{\text {wall }}}{R_{\text {cyl }}} H,
$$

where $R_{\mathrm{cyl}}$ is the radius of the ice cylinder. Owing to wall melting, the downward ice velocity that causes drag on the sphere is not equal to the basal melt rate. Due to the finite size of the spheres and the necessity to compare drag forces on spheres both on and well above the bed, wall melting cannot be eliminated from the analysis since its effects vary with vertical position (Eqn (5)). This wall melting causes radial extension of ice, similar to, but more general than, the exclusively longitudinal extension that was considered by Hallet (1981) but never explicitly included in contact-force calculations. Thus, wall melting provides a fundamental component of downward flow that affects contact forces. In the experiments presented here, radial extension is equal to the coefficient of the second term on the right-hand side of Eqn (5), i.e. $\dot{\varepsilon}_{r r}=2 \dot{m}_{\text {wall }} / R_{\text {cyl }}$.

Downward ice velocity is also measured with two linear variable differential transducers (LVDT, Sensotec model 0603611-02). To measure the downward ice movement using a LVDT, a Delrin ${ }^{\circledR}$ disk, threaded onto the end of a steel rod, is frozen horizontally into the ice, $90 \mathrm{~mm}$ above the bed. The steel rod extends vertically upward through the ice and out of a sealed hole in the chamber lid (Fig. 2). Downward movement of the ice carries the Delrin ${ }^{\circledR}$ disk and steel rod downward. Two LVDTs are mounted on a fixed frame above the chamber: one records the downward movement of the steel rod, while the other records the downward movement of the ice-chamber lid.

In both isolated-sphere and contact-force experiments, markers are frozen into the ice to record the deformation profile near the sphere. Four lengths of taut thread are frozen horizontally in the ice, $50 \mathrm{~mm}$ above the sphere. Downward movement of ice results in its deformation around the sphere, and deflection of the threads.

All data are logged on a PC equipped with National Instruments Labview software. Data are sampled and stored approximately once every $20 \mathrm{~s}$.

\section{Experimental procedure}

To begin setting up an experiment, a cylinder of ice is constructed within the ice chamber. Ice is made by setting the walk-in freezer to $-5^{\circ} \mathrm{C}$ and freezing deionized water. The ice is then crushed and sieved to obtain grain sizes between 2 and $4 \mathrm{~mm}$. Ice grains are mixed with cooled water and frozen in $6 \mathrm{~mm}$ thick layers inside the ice chamber. This technique provides uniformly sized crystals without preferred orientation. The Delrin ${ }^{\circledR}$ sphere, thermistors, ice displacement markers (threads) and Delrin ${ }^{\circledR}$ disk/steel rod are frozen into the cylinder during ice construction.
In isolated-sphere experiments the ice chamber is inverted during construction of the ice cylinder. The ice-chamber lid is slid into place before beginning ice construction. Ice layers are built until the cylinder is filled with ice. The base plate is then installed, and the ice chamber is rotated upright. The ice chamber is then centered under the hydraulic press, and the ice-chamber lid is attached to the piston of the hydraulic press.

The experimental procedure for contact-force experiments is the same as that for isolated-sphere experiments, except for the building of the ice cylinder. In contact-force experiments the ice chamber is upright during ice construction. Prior to building ice, the base plate is inserted into the base of the ice chamber and the sphere is then installed on the bed, directly over the force-transmitting rod (Fig. 2). Ice is then built layer-by-layer around the sphere. Thermistors, displacement markers and the Delrin ${ }^{\circledR}$ disk/steel rod are frozen into the ice at appropriate locations. When ice construction is complete, the ice-chamber lid is installed, and the ice chamber is positioned beneath the hydraulic press.

The freezer is then warmed to $+2{ }^{\circ} \mathrm{C}$, a small downward stress of $50 \mathrm{kPa}$ is applied to the ice and the water/glycol fluid at $0.0^{\circ} \mathrm{C}$ is circulated through the periphery of the apparatus. When thermistors in the ice indicate that it has warmed to its pressure-melting temperature and both LVDT sensors record downward movement, the downward stress on the ice is increased to $1000 \mathrm{kPa}$. This value is commensurate with a glacier $\sim 110 \mathrm{~m}$ thick.

With a load on the ice and melting occurring at the bed, ice flows towards the bed, exerting a drag force on the stationary sphere. When drag on the sphere is steady, the temperature of the fluid circulating to the base plate is increased by $\sim 0.2^{\circ} \mathrm{C}$; fluid circulated to the ice-chamber wall and lid is kept at the ice melting temperature. Increasing the fluid temperature in only the base plate increases the rate of ice melting only at the base of the ice cylinder, causing an increase in downward ice velocity. When the downward ice velocity and drag on the sphere become steady, fluid temperature in the base plate is again increased by $\sim 0.2^{\circ} \mathrm{C}$, thereby increasing the melt rate at the bed and downward ice velocity. This process is repeated until downward ice velocities of $\sim 2 \mathrm{~mm} \mathrm{~d}^{-1}$ are attained. This ice velocity is of the same order as maximum rates of ice convergence toward the bed along stoss bedrock surfaces, where abrasion is most pronounced. When drag becomes steady at this maximum velocity, rates of melting at the bed are incrementally decreased. This process is continued until the hydraulic cylinder is at its maximum reach and a downward stress can no longer be applied to the ice. The full stroke of the cylinder piston is $51 \mathrm{~mm}$. In total about 10-15 steady-state measurements can be made during an experiment.

After experiments are completed, the ice cylinder is removed from the ice chamber and dissected. This dissection allows displacement markers in the ice and separation of ice from the sphere, which occurred in all experiments, to be measured and photographed. The ice, initially white in appearance due to air bubbles, becomes clear several days into an experiment.

\section{RESULTS}

Seven experiments were conducted and assigned numbers based on the order in which they were conducted. However, experiments 2-4 were unsuccessful due to various 


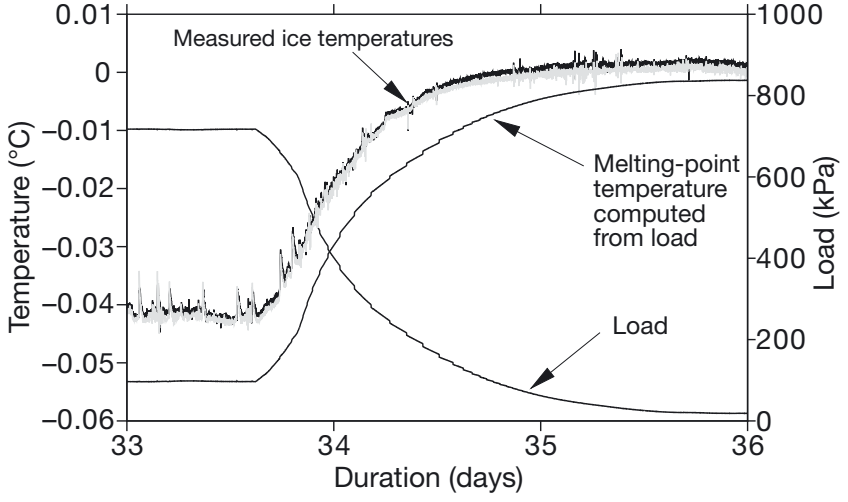

Fig. 4. Measured applied load by the piston and temperatures in ice at the end of experiment 1 during the unloading phase. The melting temperature computed from the applied load using a ClausiusClapeyron constant equal to $7.42 \times 10^{-8} \mathrm{~K} \mathrm{~Pa}^{-1}$ is also shown.

mechanical failures associated with conducting the first experiments with a sphere on the bed (contact-force experiments). No reliable, and hence usable, data were obtained from these experiments, which served effectively as shakedown tests of the custom-built apparatus. Also, the temperature of the chamber fluid was not measured during experiment 1 , and LVDT measurements were flawed due to meltwater leaking from the chamber lid. Hence, no reliable estimates of wall melting are available for this experiment. In total, one isolated-sphere and two contact-force experiments were successful (Table 1).

\section{Ice temperature}

A requirement of these experiments is that ice be at its pressure-melting temperature. This was demonstrated before and after each experiment when changes in ice loading modified the ice temperature according to the slope of the Clausius-Clapeyron equation. Figure 4 illustrates the response of two thermistors in the ice $\sim 10 \mathrm{~cm}$ above the bed at the end of experiment 1 during unloading. Temperature increased in accord with the expected change in load. Measured temperatures before unloading were slightly higher $\left(-0.042^{\circ} \mathrm{C}\right)$ than the melting temperature expected under a load of $700 \mathrm{kPa}\left(-0.053^{\circ} \mathrm{C}\right)$, probably owing to frictional forces that prevented transmitting the full load of the piston to the ice (the pressure in the ice was not measured directly). As expected, this frictional loss decreased during unloading.

\section{Bed water pressure}

During experiments, water pressures at the bed were above atmospheric and often fluctuated by as much as $400 \mathrm{kPa}$. These fluctuations had little effect on the steady drag force. During experiments 1-3, simultaneous water-pressure measurements made by sensors located $46 \mathrm{~mm}$ apart on the bed indicated that water pressure was not uniform across the bed, with higher pressure and smaller-amplitude fluctuations at the center of the ice chamber. At the end of experiment 3 , the water-pressure sensor located near the center of the base plate failed. The sensor was not replaced, owing to a design flaw that made its location vulnerable to leakage into the sensor, leaving only one working water-pressure sensor for the remaining four experiments.
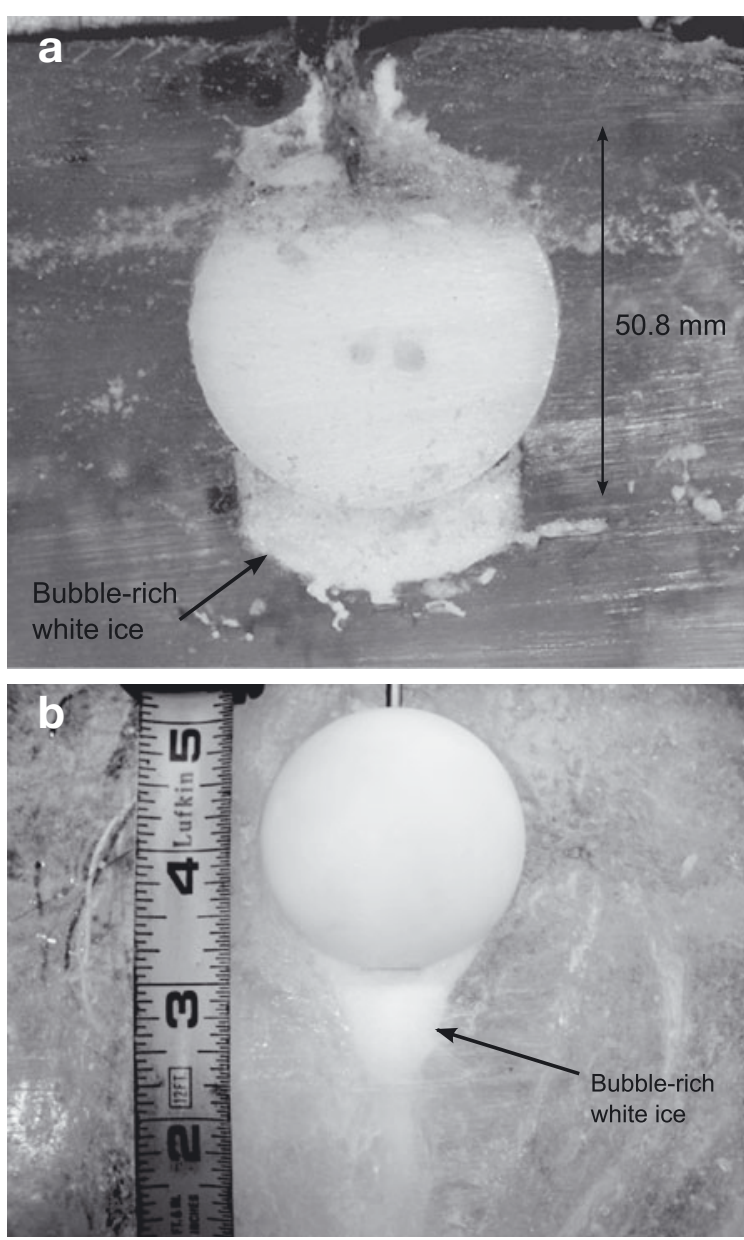

Fig. 5. Cavity of bubble-rich ice in the lee of the isolated sphere at the end of (a) experiment 1 and (b) experiment 6, indicating the presence of a water cavity during the experiments. Water froze when ice was stored in a freezer after the experiments. Scale in (b) is in inches. Although not clearly visible, radial laminations were observed in (b).

\section{Cavities and ice deformation}

At the conclusions of experiments, a vertical cross section of the ice block was exposed so deformation markers and ice surrounding the sphere could be observed. During isolatedsphere experiments, a region of white ice containing air bubbles formed on the lee side of the sphere (Fig. 5). In experiment 1, the region of altered ice was $10 \mathrm{~mm}$ in length with near-vertical sides (Fig. 5a). In experiment 6 , this region was $22 \mathrm{~mm}$ in length, had tapered sides

Table 1. Summary of successful experiments

\begin{tabular}{lcccr}
\hline & \multicolumn{4}{c}{ Experiment } \\
& $1^{*}$ & 5 & 6 & 7 \\
\hline Type & Isolated & Contact & Isolated & Contact \\
Ice pressure $(\mathrm{kPa})$ & 700 & 1000 & 1000 & 1000 \\
Water pressure $^{\dagger}(\mathrm{kPa})$ & 600 & 500 & 400 & 600 \\
Duration (days) & 36 & 26 & 21 & 20 \\
& & & & \\
\hline
\end{tabular}

\section{* Only partial data available.}

${ }^{\dagger}$ Experiment average to nearest $100 \mathrm{kPa}$ of record of piezometer nearest the perimeter of the ice chamber. 

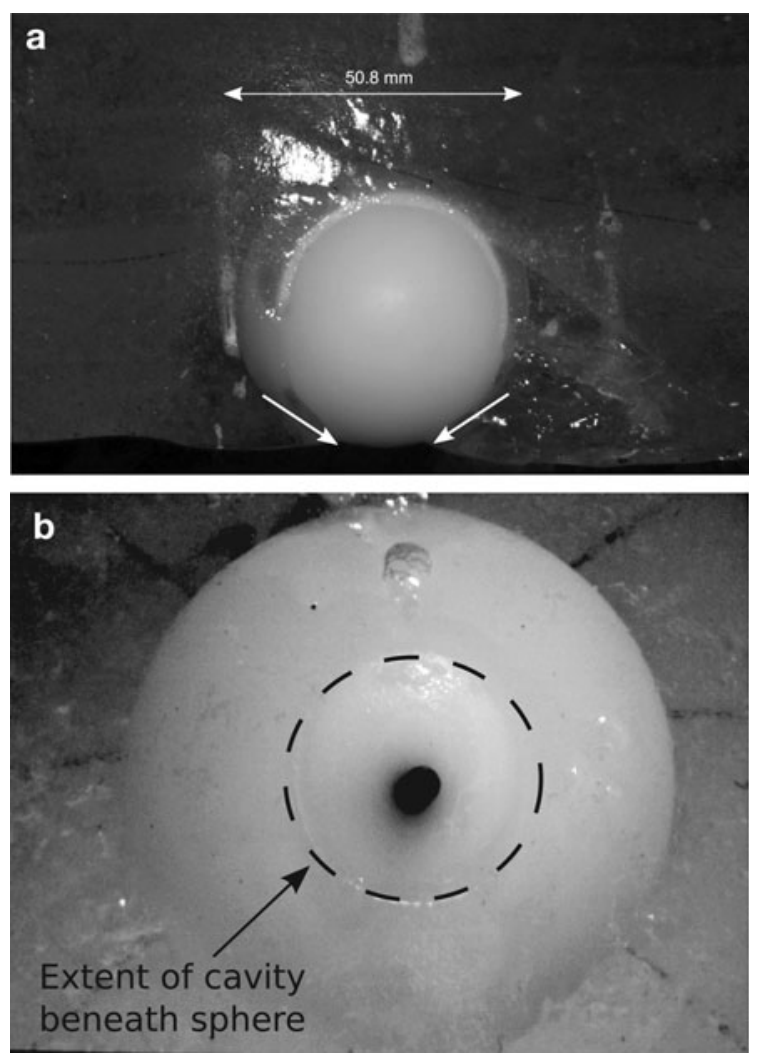

Fig. 6. Cavity beneath sphere after contact-force experiment 5 . (a) Side view with arrows showing contact line between cavity and sphere. (b) Bottom view.

and contained radially oriented laminations (Fig. 5b). No empty cavity was present beneath the sphere, but in both experiments sufficient time passed before dissection of the ice block ( $>1$ day) for water in the cavity to freeze after the experiment was concluded. During contact-force experiments a cavity again formed beneath the sphere. Post-experimental observations show a line demarcating the contact between the ice-covered and ice-free portion of the sphere (Fig. 6a). The radially symmetric cavities (Fig. 6b) had plan-view areas of 254 and $133 \mathrm{~mm}^{2}$ in experiments 5 and 7 ,

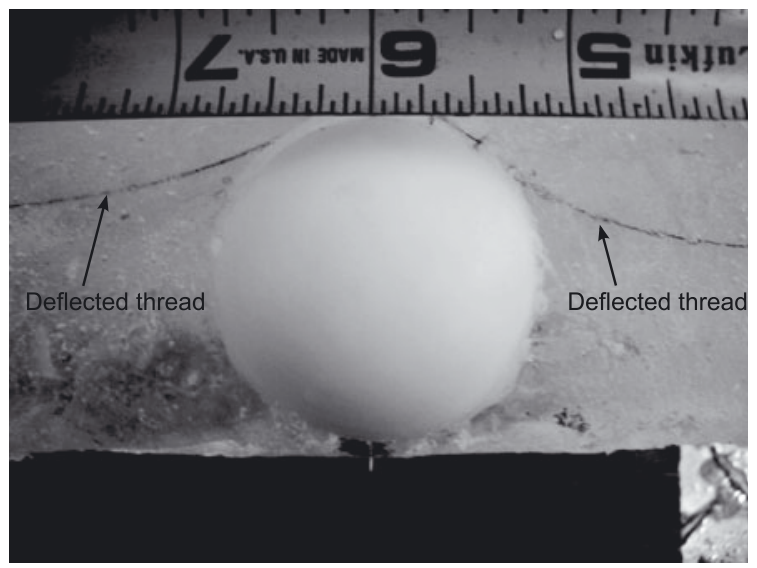

Fig. 7. Photograph of deflected threads after experiment 7, a contactforce experiment. At the start of the experiment, the threads were horizontal and $50 \mathrm{~mm}$ above the top of the sphere. As ice moved downward, threads moved with it. Scale is in inches.

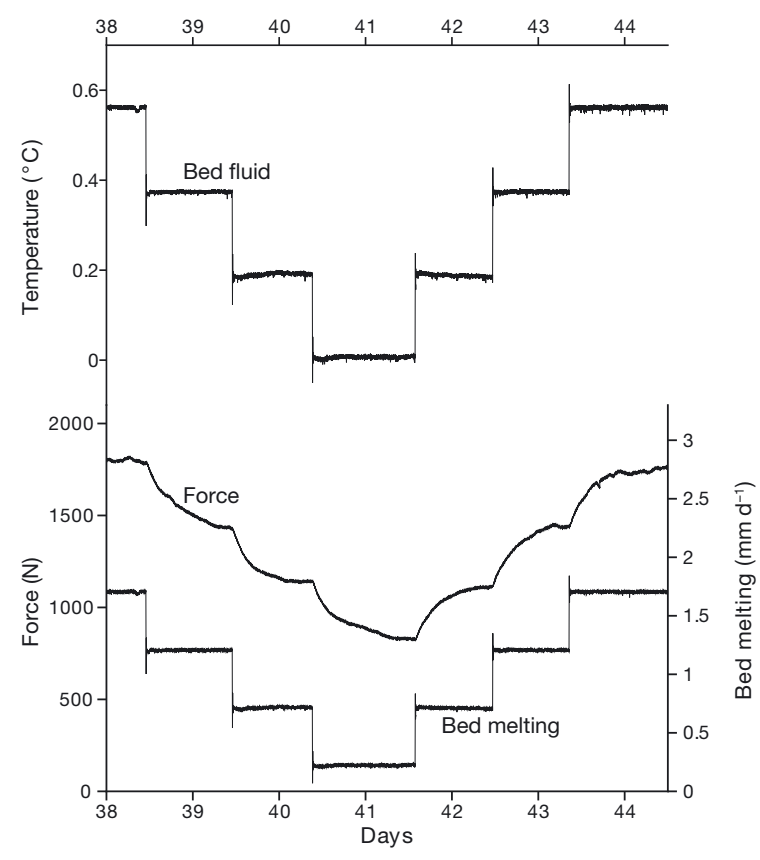

Fig. 8. Sample dataset (experiment 6) showing six incremental changes in bed fluid temperature and resulting changes in bed melting and drag force over a period of 6 days.

respectively. Positive water pressures measured at the ice/bed interface indicate that these cavities were filled with water during the experiments.

Threads (deformation markers) that were initially frozen horizontally in the ice became deflected around the sphere as ice moved downward (Fig. 7). Deformation markers indicated that there was a lateral monotonic decrease toward the sphere in the downward velocity of ice.

\section{Forces}

In both isolated-sphere and contact-force experiments, drag force was a function of downward ice velocity. Incrementally changing the temperature of the fluid circulating through the base plate changed the vertical temperature gradient in the bed and basal melt rates, thereby affecting the downward ice velocity. Reasonably steady bed temperatures, melt rates and downward ice velocities were attained within $\sim 1$ hour of changing the temperature of the basal fluid. Reasonably steady drag forces were reached 1-2 days after changes in downward velocity, with ice displacements of $\sim 0.5-$ $1.5 \mathrm{~mm}$ required to reach a steady drag. Steady downward ice velocity was always directly correlated to the steady drag force (see Fig. 8). All measurements of drag force, bed and chamber-wall melt rates (using Eqns (3) and (4)) are given in Table 2.

Figure 9 displays data of Table 2 using a normalized drag force as a function of a scaled ice velocity for both experimental configurations. We consider Newtonian ice flow (where $n=1$, Eqn (2)) without regelation first, to explore whether our data can be fitted with this simplest of constitutive laws for ice. The drag force, $F_{\mathrm{d}}$, whether for an isolated sphere or a sphere in contact with the bed, then scales as

$$
F_{\mathrm{d}}=\alpha \eta R_{\mathrm{sph}} V,
$$

where $\alpha$ is a constant that depends only on the ice-flow geometry, $\eta$ is the ice viscosity, $R_{\text {sph }}$ is the radius of the 
Table 2. Steady-state parameter values of successful experiments

\begin{tabular}{|c|c|c|c|c|}
\hline Experiment & Type & $\begin{array}{c}\dot{m}_{\text {bed }} \\
\mathrm{mm} \mathrm{d}^{-1}\end{array}$ & $\begin{array}{c}\dot{m}_{\text {wall }} \\
\mathrm{mm} \mathrm{d}^{-1}\end{array}$ & $\begin{array}{l}F_{\mathrm{d}} \\
\mathrm{N}\end{array}$ \\
\hline 1 & Isolated & $\begin{array}{l}0.19 \\
0.33 \\
0.54\end{array}$ & $\begin{array}{c}\text { na* } \\
\text { na } \\
\text { na }\end{array}$ & $\begin{array}{l}578 \\
672 \\
792\end{array}$ \\
\hline 5 & Contact & $\begin{array}{l}0.80 \\
1.30 \\
1.80 \\
1.29 \\
0.80 \\
0.30 \\
0.80 \\
1.29 \\
1.77 \\
1.28 \\
0.79 \\
0.29 \\
0.29 \\
0.79\end{array}$ & $\begin{array}{l}0.25 \\
0.26 \\
0.26 \\
0.25 \\
0.26 \\
0.31 \\
0.30 \\
0.31 \\
0.31 \\
0.31 \\
0.34 \\
0.32 \\
0.32 \\
0.27\end{array}$ & $\begin{array}{r}1167 \\
1186 \\
2006 \\
1747 \\
1309 \\
855 \\
1110 \\
1603 \\
2010 \\
1784 \\
1346 \\
870 \\
713 \\
892\end{array}$ \\
\hline 6 & Isolated & $\begin{array}{l}0.24 \\
0.71 \\
1.21 \\
1.71 \\
1.20 \\
0.72 \\
0.22 \\
0.71 \\
1.20 \\
1.71 \\
2.20 \\
0.67\end{array}$ & $\begin{array}{l}0.24 \\
0.22 \\
0.21 \\
0.22 \\
0.20 \\
0.20 \\
0.18 \\
0.20 \\
0.19 \\
0.18 \\
0.19 \\
0.18\end{array}$ & $\begin{array}{r}878 \\
1228 \\
1510 \\
1770 \\
1414 \\
1116 \\
806 \\
1088 \\
1414 \\
1732 \\
2032 \\
950\end{array}$ \\
\hline 7 & Contact & $\begin{array}{l}0.62 \\
1.18 \\
1.66 \\
1.17 \\
0.67 \\
0.19 \\
0.33 \\
0.73 \\
1.30 \\
1.81 \\
1.31 \\
0.82 \\
0.32\end{array}$ & $\begin{array}{l}0.24 \\
0.25 \\
0.25 \\
0.25 \\
0.26 \\
0.24 \\
0.24 \\
0.25 \\
0.23 \\
0.22 \\
0.21 \\
0.22 \\
0.21\end{array}$ & $\begin{array}{r}1145 \\
1425 \\
1847 \\
1485 \\
1032 \\
646 \\
666 \\
1003 \\
1625 \\
2134 \\
1791 \\
1333 \\
825\end{array}$ \\
\hline
\end{tabular}

*Not available.

sphere and $V$ is the far-field ice velocity. In the experiments, $\checkmark$ resulted from both bed and chamber-wall melting and is given by Eqn (5). Substituting Eqn (5) into (6) yields

$$
F_{\mathrm{d}}=\mathcal{A} \dot{m}_{\text {bed }}+\mathcal{B} \dot{m}_{\text {wall }}
$$

where

$$
\begin{aligned}
& \mathcal{A}=\alpha \eta R_{\mathrm{sph}} \\
& \mathcal{B}=\alpha \eta R_{\mathrm{sph}} \frac{2 H}{R_{\mathrm{cyl}}},
\end{aligned}
$$

and $H$ is an unknown distance above the bed. The coefficient $\alpha$ is determined numerically (see Appendix) for the isolatedsphere experiment (experiment 6 including the effect of the cavity) for the case $\dot{m}_{\text {wall }}=0$ then $\alpha=17.29$. For each experiment, fitting data (Table 2) to Eqn (7) yields the values of $\mathcal{A}$ and $\mathcal{B}$. For the isolated-sphere experiment

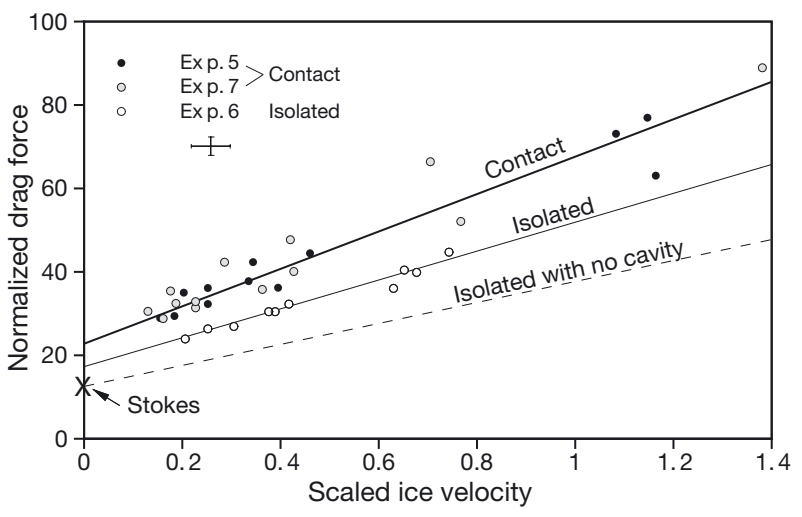

Fig. 9. Normalized drag force (Eqn (10)) as a function of scaled ice velocity (Eqn (11)) for isolated-sphere and contact-force experiments and for an isolated-sphere without cavity. Error bars shown beneath the legend are estimated based on sensor accuracy, resolution of the data-acquisition system and errors in sensor placement. Each circle represents one steady-state measurement. Lines are linear fits. The symbol $\mathrm{X}$ shows the solution of Stokes for a slippery sphere.

(experiment 6), the ice viscosity, $\eta$, can be determined from Eqn (8), since $\alpha$ is known. Knowing $\eta, H$ can be determined from Eqn (9). Assuming the viscosity of ice remains the same from one experiment to the next (a reasonable assumption based on the uniform ice-making procedure), the values of $\alpha$ and $H$ can also be determined for the contact-force experiments (experiments 5 and 7) using Eqns (8) and (9). Values of $\mathcal{A}, \mathcal{B}, \eta, \alpha$ and $H$ are given in Table 3 . The normalized drag force, $F_{d}^{\star}$, and the scaled velocity, $V^{\star}$, used in Figure 9 are

$$
F_{\mathrm{d}}^{\star}=\frac{F_{\mathrm{d}}}{\eta R_{\mathrm{sph}} \dot{m}_{\text {bed }}}
$$

and

$$
V^{\star}=\frac{H}{R_{\text {cyl }}} \frac{\dot{m}_{\text {wall }}}{\dot{m}_{\text {bed }}} .
$$

Also shown in Figure 9 is the drag force (dashed line) for the case of an isolated sphere in ice with no lee cavity. For $\dot{m}_{\text {wall }}=0$ (Stokes's law for a slippery sphere, symbol $\mathrm{X}$ in Fig. 9), the value of $\alpha$ is known analytically (Lliboutry and Ritz, 1978), and is 1.37 times smaller than the one computed numerically for the isolated-sphere experiment. This difference is due to the presence of both the cavity and the chamber wall, that effectively force ice to flow at a faster rate near the sphere than if no wall existed. In constructing the dashed line of Figure 9, it was assumed that the effect of

Table 3. Fitted parameters of Eqns (6-8) for the isolated-sphere and contact-force experiments

\begin{tabular}{lccc}
\hline Type : & Isolated & Contact & Contact \\
No.: & 6 & 5 & 7 \\
\hline $\mathcal{A}\left(\mathrm{N} \mathrm{s} \mathrm{m}^{-1}\right)$ & $5.7 \times 10^{10}$ & $7.24 \times 10^{10}$ & $7.87 \times 10^{10}$ \\
$\mathcal{B}\left(\mathrm{N} \mathrm{s} \mathrm{m}^{-1}\right)$ & $2.6 \times 10^{11}$ & $1.53 \times 10^{11}$ & $1.70 \times 10^{11}$ \\
$\alpha$ & 17.29 & 21.71 & 23.60 \\
$\eta($ Pa s$)$ & $1.31 \times 10^{11}$ & $1.31 \times 10^{11}$ & $1.31 \times 10^{11}$ \\
$H(\mathrm{~m})$ & 0.240 & 0.106 & 0.108 \\
$H / R_{\mathrm{cyl}}$ & 2.39 & 1.06 & 1.08 \\
\hline
\end{tabular}




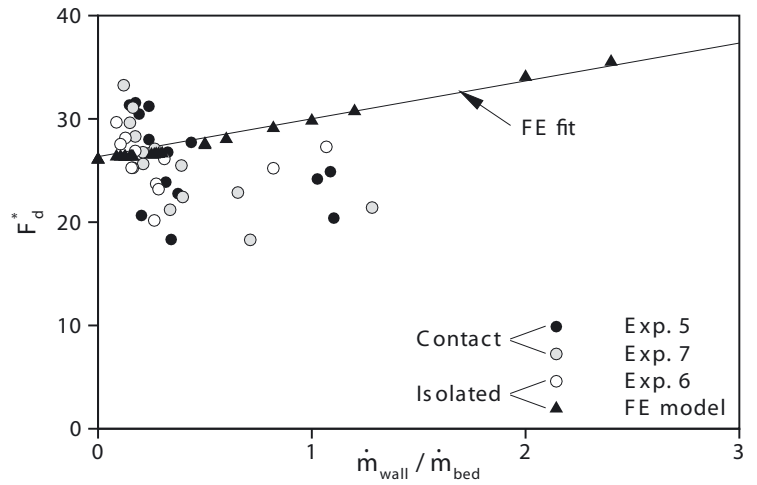

Fig. 10. Plot of normalized drag force, $F_{d}^{\star}$, (Eqn (13)) as a function of $\dot{m}_{\text {wall }} / \dot{m}_{\text {bed }}$ for data of experiments 5-7 (circles) and finite-element model (FE) with $n=3$ (black triangles and black line for fit). Measurements are plotted assuming $B / 2=2.7 \times 10^{5} \mathrm{Pas}^{1 / 3}$.

wall melting on the drag force (the slope of the line) is linear and given by the parameter $\mathcal{B}$, which depends on $\alpha$.

\section{DISCUSSION}

\section{Effect of bed on drag force}

The most fundamental outcome of these experiments is the estimation of the bed influence factor, $\phi$, on the drag force exerted by ice on a particle subjected to downward ice flow. Results of Figure 9 indicate that $\phi=1.8$, i.e. the contact force between a spherical particle and the bed is slightly less than twice Stokes's drag force (Newtonian, slippery sphere, no cavity, infinite medium). This value of $\phi(1.8)$ is within values determined in experiments by Iverson (1990) (1.33.0) and is close to the value assumed by Hallet (1981) (2.4). It is also of the same order of magnitude as values obtained by Cohen and others (2005) (1-4) using a numerical model with non-Newtonian ice $(n=2,3)$ and a ratio of water film thickness to sphere radius between $10^{-2}$ and $10^{-1}$. This ratio was $6 \times 10^{-2}$ and $2 \times 10^{-2}$ in experiments 5 and 7 , respectively, based on post-experimental observations of cavity sizes beneath the sphere (Fig. 6). However, ice in the present experiments appears to behave more like a Newtonian fluid (see discussion below) and in that case, numerical calculations by Cohen and others (2005) indicated $\phi \sim 10-100$. These large values resulted from imposing the basal melt rate as a velocity boundary condition at the bed of their numerical model and the requirement that mass continuity be maintained as ice melted at the bed in the narrow space between it and the sphere. The ice-continuity requirement causes steep pressure gradients to drive ice flow beneath the sphere at a rate commensurate with the basal melt rate, which in turn requires low pressure in the ice there. This low pressure may not, however, be physically sustainable because, under realistic conditions, water under pressure will squeeze in the gap and freeze there. The low pressure computed numerically beneath the sphere results in enhanced drag and a high bed-enhancement factor - an explanation for the high friction measured by Iverson and others (2003) and Cohen and others (2005) at the bed of Engabreen that now appears unlikely.

\section{Ice rheology}

Figure 9 indicates that measured forces depended linearly on ice velocity, in accord with Eqn (6) and with finite-element modeling (see Appendix) for Newtonian ice. We also attempted to fit the data to a power-law fluid with $n=3$. For $n=3$, substituting Eqn (5) into Eqn (2) yields

$$
F_{\mathrm{d}}=\alpha R^{2 / 3} \dot{m}_{\text {bed }}^{1 / 3} \frac{B}{2}\left(1+\frac{2 H}{R_{\text {cyl }}} \frac{\dot{m}_{\text {wall }}}{\dot{m}_{\text {bed }}}\right)^{1 / 3} .
$$

Results of finite-element calculations fit this equation relatively well, but measurements do not: Figure 10, which shows the normalized drag force,

$$
F_{\mathrm{d}}^{\star}=\frac{2 F_{\mathrm{d}}}{B R_{\mathrm{sph}}^{2 / 3} \dot{m}_{\mathrm{bed}}^{1 / 3}}
$$

as a function of $\dot{m}_{\text {wall }} / \dot{m}_{\text {bed, }}$ clearly indicates that ice in our experiments did not behave as a nonlinear viscous fluid with $n=3$.

Newtonian ice flow is also consistent with the pattern of thread deflection observed in the experiments. Lliboutry and Ritz (1978) calculated the velocity field around a sphere in ice and found that when $n$ exceeded 1.5, ice velocity near the sphere along its equatorial plane became larger than the uniform far-field velocity and declined to a value less than the far-field velocity immediately adjacent to the sphere. This larger velocity is caused by a lower effective viscosity near the sphere, owing to the nonlinear, shear thinning, rheology. Hooke and Iverson (1985) integrated these velocities over time to show that deformation markers in ice will display a bulge (a zone with ice displacements greater than the farfield value) near inclusions. The threads of this study display no such bulge. Rather there was a monotonic decline in total displacement from the far field to the sphere's surface (Fig. 7). Thus, this deformation pattern indicates that $n$ for the ice in this study was less than 1.5.

Numerical estimates of deviatoric stress during the experiments indicate that it was relatively low, $\sim 100 \mathrm{kPa}$. Low stresses in ice should favor a low stress exponent (e.g. Mellor and Testa, 1969; Dahl-Jensen and Gundestrup, 1987; Duval and Castelnau, 1995), as should the presence of water along grain boundaries, which reduces dislocation pile-up and hardening (De La Chapelle and others, 1998). Furthermore, ice moving past the sphere is subjected to a constantly varying stress field and hence is always in the transient creep phase, a creep regime in which stress is nearly linearly proportional to strain rate (Jacka, 1984).

Data from experiments with the isolated sphere (Table 3) combined with finite-element modeling indicate a Newtonian ice viscosity of $1.3 \times 10^{11} \mathrm{Pas}$, in accord with other measurements (e.g. Cohen, 2000). Assuming a power-law exponent of $n=3$ in the numerical model requires a value of $B$ of $2-14 \times 10^{6} \mathrm{Pas}^{1 / 3}$ to match data, a factor 10 smaller than expected $\left(\sim 2-10 \times 10^{7} \mathrm{Pas}^{1 / 3}\right.$; Cohen, 2000). This discrepancy further indicates that ice in these experiments behaved nearly linearly.

\section{Cavity formation and regelation}

The bubbly, and hence white, ice observed beneath the sphere in the isolated-sphere experiments (Fig. 5) indicates that a cavity probably formed, with water that did not drain from the cavity after experiments and froze during the time between the conclusions of experiments and dissection of the ice block. Without a drainage path through the ice to the drains in the bed, water in the cavity was likely under a pressure comparable to the ambient ice pressure beneath the sphere. The difference in cavity shape between 
experiments 1 and 6 is likely due to the higher ice pressure in experiment 6 (Table 2).

Why did cavities form? In the case of the contact-force experiments, the sphere, acting as a foreign substrate, is surrounded by a thin liquid film (Dash and others, 2006) which meets the water film between the ice and the bed along a curved surface. That curved surface encroaches into the ice in the gap between the sphere and the bed, increasing the quantity of liquid water beneath the sphere. The rate of ice flow in the gap will depend on the water pressure in the cavity. Low water pressure would help ice move into the small gap between the sphere and the bed, increasing the pressure drop ice undergoes beneath the sphere and thus increasing the drag force on the sphere (Cohen and others, 2005). Low water pressure beneath the sphere, however, would prevent water from draining into the thin water film that is presumably at a pressure that is close to the ice overburden pressure. In the experiment, water pressure was higher near the sphere than near the perimeter of the ice chamber, implying water flowed away from the sphere. The water pressure near the sphere was sufficiently high to prevent ice from squeezing into the narrow gap, helping to maintain a water cavity there. The pressure in the gap beneath the sphere also determines the temperature there and the resulting heat fluxes from the bed and into the sphere. These fluxes together with the latent heat of freezing will determine whether ice in the gap remains liquid or frozen.

The likely explanation for the cavity that apparently formed in the isolated-sphere experiments is less obvious. The cavity may reflect incomplete refreezing associated with regelation: pressure-driven melting and refreezing. Such incomplete refreezing has been commonly observed in regelation experiments in which various inclusions are dragged through temperate ice (e.g. Townsend and Vickery, 1967; Drake and Shreve, 1973). By providing another flow mechanism, regelation would decrease the drag force ice exerts on the sphere as it moves past it. To assess the contribution of regelation, Watts (1974) provided an analytical solution for the drag force, $F_{\mathrm{d}}$, which accounts for both viscous deformation and regelation past an isolated sphere. This solution assumes ice has a linear rheology, an assumption that fits our measurements. His expression for the drag force is

$$
F_{\mathrm{d}}^{\mathrm{reg}}=4 \pi \eta V \frac{R^{3}}{R_{\star}^{2}+R^{2}}
$$

where $\eta$ is the ice viscosity, $V$ is the far-field ice velocity, $R$ is the radius of the sphere and $R_{\star}$ is a transition sphere radius for which viscous flow and regelation contribute equally to the drag. For a Delrin ${ }^{\circledR}$ sphere, $R_{\star}=0.0046 \mathrm{~m}$ (Cohen and others, 2005; their eqn (15). The drag force computed from Eqn (14) is $5 \%$ less than if regelation was neglected. Thus, according to this model, the effect of regelation is negligible in comparison with other factors that influence the drag force, such as cavity shape and melting at chamber walls.

\section{CONCLUSION}

The most important implication of this study is that contact forces between spherical particles and a bed are slightly less than twice the value of the drag force exerted on an isolated particle by Newtonian ice (Stokes's law for a slippery sphere), thus confirming earlier measurements (Iverson, 1990) and analytical estimates (Hallet, 1981). Drag forces past particles can be correctly estimated using Stokes's law for a slippery sphere. Effects of regelation and cavity water pressure appeared to be negligible. Ice behaved linearly (Newtonian), probably owing to small and transient stresses.

These laboratory experiments provide no support for explanations of high debris/bed friction that depend on high contact forces (Iverson and others, 2003; Cohen and others, 2005). They also provide no support for the high contact forces required to bring laboratory measurements of rockon-rock wear rates into agreement with rates of subglacial abrasion (Lee and Rutter, 2004). Other variables that affect friction and abrasion may be more uncertain and important to consider. These include the debris concentration, the grain-size distribution of particles in ice in contact with the bed, bed geometry and hardness contrast between debris and bed, which can vary through orders of magnitude. Data that definitively bear on the effects of these variables are, for the most part, unavailable.

\section{ACKNOWLEDGEMENTS}

This project was funded by the US National Science Foundation grant EAR0615781. We thank D. Hultman for his contribution to the design of the laboratory device. We thank B. Hallet and an anonymous reviewer for suggesting improvements to the manuscript.

\section{REFERENCES}

Boulton GS (1974) Processes and patterns of glacial erosion. In Coates, DR, ed. Glacial geomorphology. State University of New York, Binghamton, NY, 41-87

Cohen D (2000) Rheology of ice at the bed of Engabreen, Norway. J. Glaciol., 46(155), 611-621

Cohen $\mathrm{D}$, Iverson $\mathrm{N}$, Hooyer $\mathrm{T}$, Fischer $\mathrm{U}$, Jackson $\mathrm{M}$ and Moore $\mathrm{P}$ (2005) Debris-bed friction of hard-bedded glaciers. J. Geophys. Res., 110(F2), F02007 (doi: 10.1029/2004JF000228)

Dahl-Jensen D and Gundestrup NS (1987) Constitutive properties of ice at Dye 3, Greenland. IAHS Publ. 170 (Symposium at Vancouver - The Physical Basis of Ice Sheet Modelling), 31-43

Dash JG, Rempel AW and Wettlaufer JS (2006) The physics of premelted ice and its geophysical consequences. Rev. Mod. Phys., 78(3), 695-741

De La Chapelle S, Castelnau O, Lipenkov V and Duval P (1998) Dynamic recrystallization and texture development in ice as revealed by the study of deep ice cores in Antarctica and Greenland. J. Geophys. Res., 103(B3), 5091-5105

Drake LD and Shreve RL (1973) Pressure melting and regelation of ice by round wires. Proc. R. Soc. London, Ser. A, 332(1588), 51-83

Duval P and Castelnau O (1995) Dynamic recrystallization of ice in polar ice sheets. J. Phys. IV [Paris], 5(C3), 197-205

Emerson LF and Rempel AW (2007) Thresholds in the sliding resistance of simulated basal ice. Cryosphere, 1(1), 11-19

Goren SL (1970) The normal force exerted by creeping flow on a small sphere touching a plane. J. Fluid Mech., 41(3), 619-625

Hallet B (1979) A theoretical model of glacial abrasion. J. Glaciol., 23(89), 39-50

Hallet B (1981) Glacial abrasion and sliding: their dependence on the debris concentration in basal ice. Ann. Glaciol., 2, 23-28

Hindmarsh RCA (1996) Cavities and the effective pressure between abrading clasts and the bedrock. Ann. Glaciol., 22, 32-40

Hooke RLeB and Iverson NR (1985) Experimental study of ice flow around a bump: comparison with theory. Geogr. Ann., 67A(3-4), 187-197

Iverson NR (1990) Laboratory simulations of glacial abrasion: comparison with theory. J. Glaciol., 36(124), 304-314 
Iverson NR and 6 others (2003) Effects of basal debris on glacier flow. Science, 301(5629), 81-84

Jacka TH (1984) The time and strain required for development of minimum strain rates in ice. Cold Reg. Sci. Technol., 8(3), 261-268

Lee AGG and Rutter EH (2004) Experimental rock-on-rock frictional wear: application to subglacial abrasion. J. Geophys. Res., 109(B9), B09202 (doi: 10.1029/2004JB003059)

Lliboutry L and Ritz C (1978) Ecoulement permanent d'un fluide visqueux non linéaire (corps de Glen) autour d'une sphère parfaitement lisse. Ann. Géophys., 34(2), 133-146

Mellor M and Testa R (1969) Creep of ice under low stress. J. Glaciol., 8(52), 147-152

Morland LW (1976) Glacier sliding down an inclined wavy bed with friction. J. Glaciol., 17(77), 463-477

Reynaud L (1973) Flow of a valley glacier with a solid friction law. J. Glaciol., 12(65), 251-258

Schweizer J and Iken A (1992) The role of bed separation and friction in sliding over an undeformable bed. J. Glaciol., 38(128), 77-92

Shoemaker EM (1988) On the formulation of the basal debris drag for the case of sparse debris. J. Glaciol., 34(118), 259-264

Townsend, DW and Vickery RR (1967) An experiment in regelation. Philos. Mag., 16(144), 1275-1280

Watts, PA (1974) Inclusion in ice. (PhD thesis, University of Bristol)

\section{APPENDIX: NUMERICAL ESTIMATES OF DRAG FORCE PAST AN ISOLATED SPHERE}

To estimate the drag force on the isolated sphere (experiment 6), we solve Stokes's equations using Elmer (http://www.csc.fi/elmer), a finite-element open-source code. The flow of ice around the isolated sphere in the ice chamber is discretized into 41336 quadratic elements. The shape of the cavity is obtained from digitizing Figure $5 \mathrm{~b}$. Boundary conditions are $\dot{m}_{\text {bed }}=1$ imposed at the top of the ice domain; $\dot{m}_{\text {wall }}$ at the ice-chamber wall; and perfect slip around the sphere. Owing to cylindrical symmetry, the problem is solved in two dimensions in an axisymmetric configuration. For $\dot{m}_{\text {wall }}=0$, the computed value of $\alpha$ (Eqn (6)) is 17.29 , a value that changed less than $0.1 \%$ with increasing mesh resolution. Numerical solutions with increasing values of $\dot{m}_{\text {wall }}$ match the linear form of Eqn (7) shown fitted to the experimental data in Figure 9 (straight lines). The ice flow and drag force are also computed for non-Newtonian ice with $n=3$ and various values of velocity at the top of the domain and ratios of top velocity there to chamber-wall velocity. Calculated drag forces are shown in Figure 10 and discussed in the main text. 